\title{
Pembuatan Brand Mark dan Motion Graphic Logo pada Rebranding Project PT Astra Graphia Information Technology
}

\author{
Hata Maulana, Dhea Zarassita \\ Program Studi Teknik Multimedia dan Jaringan \\ Jurusan Teknik Informatika dan Ko mputer \\ Politeknik Negeri Jakarta \\ Depok, Indonesia \\ hata.maulana@tik.pnj.ac.id, dheazarass@gmail.com
}

Diterima: 5 Oktober 2017. Disetujui: 10 november 2017. Dipublikasikan : November 2017

\begin{abstract}
Abstrak - PT Astra Graphia Information Technology merupakan sebuah perusahaan yang bergerak di bidang teknologi dan telah berdiri selama 13 tahun. PT Astra Graphia Information Technology (AGIT) membutuhkan sebuah brand mark baru yang menggambarkan identitas perusahaan agar dapat tetap bersaing di dunia bisnis IT yang terus bergerak semakin canggih. Rebranding Project merupakan sebuah proyek pembuatan brand mark dan motion graphic logo yang dilakukan oleh Departemen Marketing. Pembuatan brand mark kemudian diterapkan dalam template brosur, presentasi dan company profile dari AGIT untuk mendukung pelaksanaan Rebranding Project. Tujuan dari proyek ini adalah memperbaharui image perusahaan, penyeragaman desain promosi perusahaan dan meningkatkan service revenue AGIT.
\end{abstract}

Kata Kunci : brand mark, motion graphic, rebranding, identitas perusahaan, adobe after effect, adobe illustrator

\section{PENDAHULUAN}

Sebuah perusahaan dalam menjalankan bisnisnya mempunyai brand dan logo tersendiri yang menjadi unsur penting dan dapat membedakannya dengan perusahaan lain. Brand dan logo merupakan sebuah tanda yang secara langsung tidak menjual, tetapi memberi suatu identitas yang pada akhirnya berfungsi sebagai alat pemasaran yang signifikan[1].

PT Astra Graphia Information Technology (AGIT) merupakan sebuah perusahaan yang bergerak di bidang teknologi dan telah berdiri selama 13 tahun. Selama belasan tahun bersaing dengan para kompetitor perusahaan IT lainnya, AGIT menggunakan satu desain brand mark yang diterapkan di berbagai media tulis maupun digital dalam menjalankan bisnisnya. Sesuai dengan [3], untuk dapat tetap bersaing di dunia bisnis IT yang terus bergerak semakin canggih, AGIT me mbutuhkan desain brand mark baru yang dapat menggambarkan identitas perusahaan yang selaras dengan pergerakan tersebut. Hal inilah yang menjadi alas an bagi Departemen Marketing AGIT untuk melakukan Rebranding Project.

Terdapat dua hal yang dikerjakan pada rebranding project ini, yaitu : pembuatan brand mark baru untuk digunakan pada template brosur, template presentasi dan company profile dan pembuatan motion graphic logo AGIT.

Rebranding project ini diharapkan dapat men ingkatkan company image dan service revenue AGIT.

\section{TINJAUAN PUSTAKA}

\section{A. Brand}

Brand adalah identitas atau nama yang mewakili produk secara keseluruhan baik produk itu sendiri, jasa yang diberikan produk tersebut, perusahaan yang memproduksi, maupun hal-hal terkait lainnya[2]. Brand bagi sebuah perusahaan merupakan komponen penting yang menjadi reputasi perusahaan. Dengan brand, perusahaan atau penjual memberikan janji untuk secara konsisten memberikan keistimewaan, manfaat dan jasa tertentu kepada pembeli[2].

\section{B. Brand Mark}

Mark atau merek adalah nama, istilah, tanda, simbol, rancangan atau kombinasi dari halhal tersebut[3]. Tujuan dari pemberian merek tidak jauh berbeda dengan brand yaitu mengidentifikasikan produk atau jasa yang dihasilkan sehingga berbeda dari produk atau jasa yang dihasilkan oleh competitor lain[3]. Brand Mark atau biasa disebut dengan tanda merek merupakan bagian dari merek yang dapat dikenali namun tidak dapat diucapkan, seperti lambang (icon), desain huruf atau nama khusus. Contoh dari 
brand mark antara lain simbol Toyota dan gambar tiga berlian Mitsubishi [3].

\section{Motion Graphic}

Motion graphic saat ini sedang menjadi tren dikalangan para desainer visual dalam pembuatan video. Hampir semua media visual bergerak menampilkan motion graphic baik sebagai tampilan pendukung seperti bumper program, iklan maupun sebagai konten utama.

Motion Graphic merupakan potongan media visual yang menggabungkan film dan desain grafis dan berbasis waktu. Elemen yang digabungkan dapat berupa animasi 2D dan 3D, video, film, tipografi, ilustrasi, fotografi dan musik[4].

\section{Rebranding}

Rebranding berasal dari kata re- yang memiliki arti"kembali" dan branding atau proses penciptaan brand image yang menghubungkan hati dan benak pelanggannya. Rebranding merupakan suatu upaya atau usaha untuk merubah atau memperbaharui sebuah brand yang telah ada agar menjadi lebih baik [5].

\section{E. Teknik Gradient Coloring}

Teknik gradient atau gradient coloring adalah teknik yang banyak dipakai dalam beragam jenis desain. Teknik ini menggabungkan lebih dari satu warna ke dalam suatu objek sehingga menghasilkan warna gradasi[5].

\section{F. Prinsip Dasar Desain Layout}

Seorang desainer grafis dalam membuat sebuah desain harus mengenal 4 prinsip desain dasar layout untuk memudahkan dalam penciptaan komunikasi visual yang efekt if dan efisien [6]. Prinsip-prinsip dasar desain layout tersebut antara lain[6-7]:

1) Sequence

Sequence atau urutan adalah prioritas penempatan konten pada layout. Bagian mana yang harus dibaca terlebih dahulu sampaike konten yang dapat dibaca terakhir. Salah satu penerapan dari prinsip ini adalah penggunaan sistem ' Z' layout.

2) Emphasis

Emphasis atau penekanan diperlukan untuk menyampaikan konten yang paling penting atau utama disampaikan sehingga tidak menimbulkan kesalahan pe mahaman.

3) Balance

Balance atau keseimbanagn berkaitan dengan peletakan konten dan ornamen desain yang tepat akan membuat pesan desain mudah tersampaikan.

4) Unity
Elemen-elemen yang dimasukkan ke dalam desain menciptakan sebuah unity atau kesatuan mulai dari warna, letak, ornamen dan jenis font yang digunakan.

5) Sistem "Z" Layout

Seperti penamaannya, tata letak pola sistem ' $Z$ ' layout membentuk huruf $Z$. Dengan sistem layout ini, pembaca akan memulai membaca desain dari bagian atas kiri, bergerak horizontal ke atas kanan lalu kemudian diagonal ke bagian kiri bawah dan terakhir ke arah horizontal bagian kanan bawah. Tata letak system ' $Z$ ' layout adalah struktur atau format standar dimana dalam bentuk huruf $\mathrm{Z}$ merupakan jalur alami penglihatan mata [7].

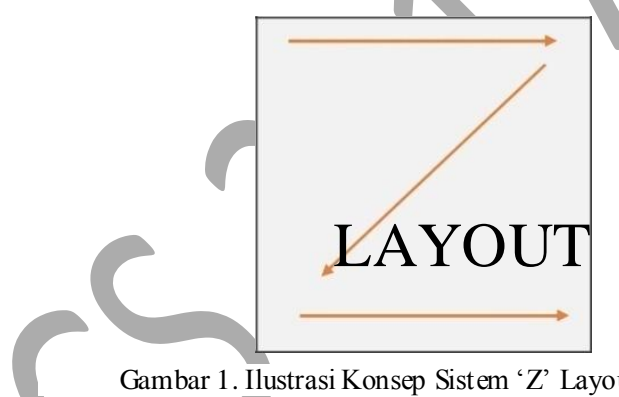

Gambar 1. Ilustrasi Konsep Sistem 'Z' Layout [7]

\section{G. Efek Turbulent Displace}

Efek Turbulent Displace merupakan sebuah efek yang ada pada software Adobe After Effects dan biasa digunakan untuk menciptakan efek turbulensi pada gambar motion. Menurut Jago, (2012), efek ini merupakan efek yang tepat untuk menambahkan tekstur dan menghidupkan pergerakan aset gambar terutama untuk membuat komposisi pergerakan dengan warna dan tekstur yang kompleks. Efek ini dapat ditemukan pada bagian efek Distort yang ada pada tools Effects \& Presets pada Adobe After Effects [8].

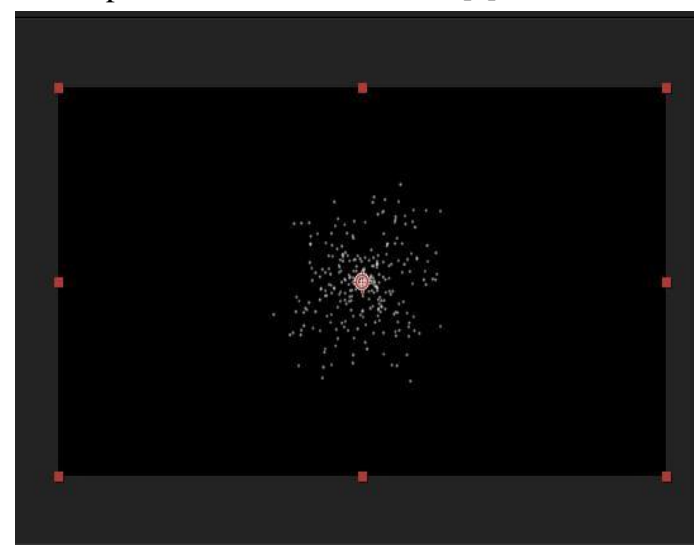

Gambar 2. Efek Turbulent Displace pada Adobe After Effects[8]

\section{H. Plug-in Trapcode Particular}

Trapcode Particular adalah sebuah plug-in sistem partikelyang membantu user untuk membuat 
efek partikel pada Adobe After Effects seperti contohnya adalah efek ledakan, asap, hujan, awan dan debu. Sistem partikel pada plug-in ini memberikanefek partikel memancar secara otomatis seakan-akan pergerakan tersebut hidup [9].

\section{Gradient Ramp}

Gradient Ramp merupakan sebuah efek yang terdapat pada Adobe After Effects dimana efek ini dapat menciptakan gradasi warna. Dengan efek ini, dapat diciptakan sebuah gradasi yang dapat dibuat linear atau radial dengan variasi posisi dan warna [10].

\section{J. Editing Audio}

Editing audio merupakan cara untuk mengedit,mempersingkat atau mengubah musik atau audio sehingga dapat dinikmati oleh pendengar. Pengeditan ini dapat diterapkan untuk audio itu sendiri saja atau dapat diterapkan dan disinkronisasikan dengan video untuk menyampaikan sebuah pesan[11].

\section{K. Rendering}

Rendering merupakan suatu tahap akhir yang biasanya digunakan dalam pembuatan sebuah video atau animasi. Menurut Bartholo Bush Sawa, rendering adalah sebuah proses dimana file editing video yang telah dibuat, diubah men jadi bentuk file video yang bisa dibuka menggunakan video player[12]. Pada produk Adobe System, software Adobe Premiere Pro atau Adobe Encoder dapat digunakan untuk me laku kan proses rendering

\section{Adobe Illustrator}

Adobe Illustrator merupakan sebuah software ilustrasi vektor ternama yang merupakan bagian dari Adobe System. Adobe Illustrator memungkinkan user untuk membuat segala jenis desain, dimulai dari grafis simple, icon, teks hingga ilustrasi yang kompleks dan terdiri dari banyak layer[13].

\section{Adobe After Effects}

Adobe After Effects adalah sebuah perangkat lunak editing video kelas dunia yang dapat digunakan untuk menambah efek, suara, animasi, bahkan efek 3D pada pengeditan video[14]. Software ini merupakan salah satu software yang ada pada produk Adobe System.

\section{N. Adobe Premiere Pro}

Adobe Premiere Pro adalah program penyunting video yang merupakan bagian dari Adobe System. Adobe Premiere Pro memfasilitasi banyak efek editing dan plug-in yang bekerja secara cepat dan mendukung banyak format file audio maupun efek video[15]. Fungsi lain dari
Adobe Premiere Pro adalah sebagai tools untuk melakukan rendering project video.

\section{METODOLOGI}

Dalam pembuatan sebuah produk multimedia, terdapat tahapan-tahapan atau alur yang harus dilakukan agar mendapatkan hasil produk multimedia yang optimal. Mengacu pada siklus pengembangan metode Villamil-Molina yang diadopsi oleh Putri, terdapat 3 tahapan metode yang dapat digunakan dalam pengembangan multimedia ini, tahap tersebut sebagai berikut [4] :

\section{1) Pra produksi}

Tahap ini merupakan tahap awal dalam pembuatan produk multimedia berupa persiapan semua data dan elemen yang berkaitan dengan produksi. Pada tahap ini dilakukan pencarian ide yang akan dituangkan dalam produk multimedia, perencanaan proses produksi berupa kerangka kerja yang akan dilakukan, pembuatan storyboard dan material collecting.

2) Produksi

Proses produksi merupakan tahap eksekusi lapangan berupa pengerjaan project yang dihasilkan dari proses pra produksi. Pada tahap ini dilakukan pembuatan semua konten produk mu ltimed ia.

3) Paska Produksi

Paska Produksi merupakan tahap penyelesaian akhir dari sebuah rangkaian produksi multimedia. Salah satu hal yang dapat dilakukan dalam tahap ini adalah distribusi, yaitu pengeluaran dan pendistribusian produk sesuai dengan kebutuhan.

\section{ANALISIS DAN PERANCANGAN}

\section{A. Pra Produksi}

Pada tahap ini, dilakukan pencarian referensi ide, pembuatan kerangka kerja, storyboard dan proses material collecting.

a) Pencarian Ide

Pencarian referensi ide dan gambaran pembuatan brand mark dilakukan dengan melakukan riset terhadap 1) Brand Mark versi lama dari A GIT, 2) Referensi desain terkini untuk sebuah brand mark di internet.

b) Pe mbuatan Kerangka Kerja

Pada tahap ini dibuat sebuah kerangka kerja yang berisi apa saja job dan detail konsep yang akan dibuat dalam pembuatan brand mark dan motion graphic logo. Kerangka kerja ini merupakan hasil diskusi bersama tim Rebranding Project dan pengumpulan informasi dari hasil 
pencarian referensi yang telah dilakukan sebelumnya.

\begin{tabular}{|c|c|l|l|}
\hline \multicolumn{5}{|c|}{ Rebranding Project } \\
\hline No. & \multicolumn{1}{|c|}{ Project } & \multicolumn{1}{|c|}{ Job } & \multicolumn{1}{c|}{ Details } \\
\hline 1 & Brand Mark & $\begin{array}{l}\text { Pembuatan iconic dari brand } \\
\text { mark terbaru }\end{array}$ & $\begin{array}{l}\text { - Dibuat dalam 2 versi desain yaitu menggunakan } \\
\text { wana Burgundy-Orange dan Full Color } \\
\text { - Penempatan iconic disesuakikan dengan } \\
\text { penempatan logo AGIT dan logo slogan AGIT } \\
\text { "Digitize Things" } \\
\text { - Hasil akhir brand mark diterapkan ke dalam: } \\
\text { Desain template brosur, template presentasi, } \\
\text { slide master dan company profile }\end{array}$ \\
\hline 2 & Animasi Logo & $\begin{array}{l}\text { Pembuatan motion graphic } \\
\text { logo AGiT }\end{array}$ & $\begin{array}{l}\text { - Motion graphic logo dibuat dalam bentuk } \\
\text { bumper untuk opening maupun closing video } \\
\text { event } \\
\text { - Konsep : "reveal logo" }\end{array}$ \\
\hline $\begin{array}{l}\text { Rebranding Project Team: } \\
\text { 1. Project Leader } \\
\text { 2. Content creator } \\
\text { 3. Designer \& Motion Grapher } \\
\text { : Denise Citra } \\
\text { : Dhea Zarassita }\end{array}$ \\
\hline
\end{tabular}

Gambar 3. Kerangka Kerja Hasil Diskusi Tim Rebranding Project

\section{c) Storyboard}

Pembuatan storyboard pada tahap pra produksi dilakukan sebagai acuan dari scene motion yang akan dibuat dalam tahap produksi motion graphic logo.

\section{d) Material Collecting}

Material collecting adalah persiapan dan pengumpulan bahan atau konten yang akan digunakan dalam pembuatan proyek multimedia. Konten yang dibutuhkan dalam pembuatan proyek ini antara lain logo dari AGIT, logo Digitize Things, sebuah backsound dan beberapa stok foto.

\section{IMPLEMENTASI DAN PEMBAHASAN}

\section{B. Produksi}

Tahap produksi merupakan tahap pelaksanaan pembuatan proyek. Tahap ini dibagi menjadi dua bagian, yaitu proses produksi brand mark dan produksi motion graphic logo.

a) Produksi Brand Mark

Pembuatan brand mark pada Rebranding Project ini dibuat menggunakan Adobe Illustrator. Tahap yang dilakukan dalam pembuatan brand mark ini adalah pembuatan iconic dengan teknik gradient coloring dan layouting.

Pembuatan Iconic dengan Teknik Gradient Coloring berdasarkan hasil diskusi dari tim Rebranding Project, bentuk atau shape dari iconic yang akan dibuat adalah line atau persegi panjang dengan warna gradient. Pe mbuatan warna gradient dilakukan dengan teknik gradient coloring menggunakan Gradient Tools yang ada pada Adobe Illustrator. Komposisi warna yang digunakan adalah komposisi transisi dari warna Burgundy-Orange sesuai dengan warna khas AGIT sebagai versi pertama dan komposisi warna colorful sebagai versi kedua. Komposisi transisi warna digabungkan dan disusun dari warna gelap menuju warna yang paling terang seperti pada Gambar 4.

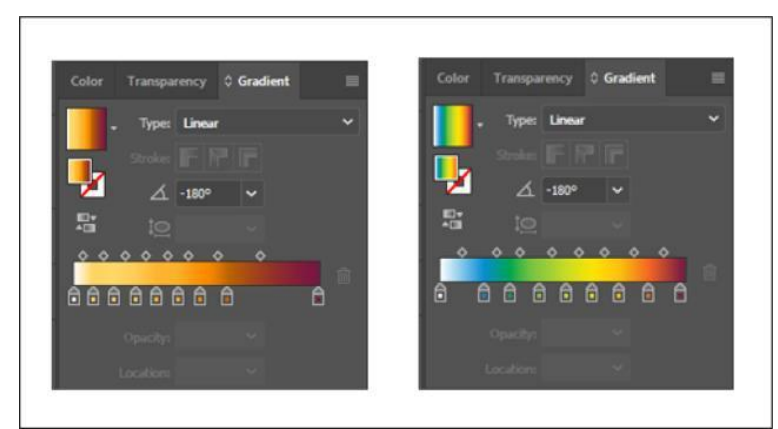

Gambar 4. Komposisi Wama Burgundy-Orange(kiri) dan Colorful (kanan) pada Gradient Tools

\section{b) Layouting}

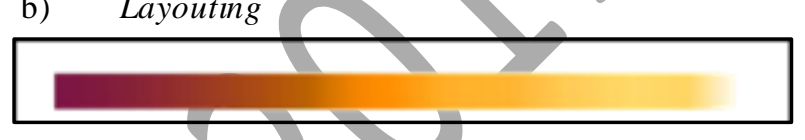

Gambar 5. Gambar 5 Hasil Iconic Versi Burgundy-Orange

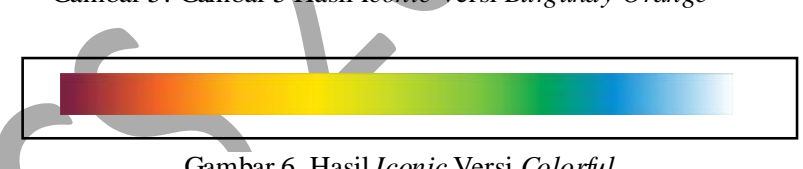

Gambar 6. Hasil Iconic Versi Colorful

Setelah proses pembuatan bentuk dan warna iconic, dilakukan proses layouting atau penempatan iconic pada layout template brosur dan presentasi. Penempatan/layouting dari icon brand mark dikombinasikan dengan logo AGIT dan logo slogan Digitize Things.

Dalam pembuatan layout digunakan salah satu dari 4 prinsip dasar desain yaitu Sequence dimana konten yang dimasukkan ke dalam layout diurutkan berdasarkan bagian mana yang harus dibaca terlebih dahulu sampai konten yang dapat dibaca terakhir. Berdasarkan prinsip tersebut, digunakan sistem ' $\mathrm{Z}$ ' layout untuk penataan letak konten.

Berdasarkan sistem ' $Z$ ' layout, pembaca akan me lihat isi layout berdasarkan aliran huruf $\mathrm{Z}$ yaitu dari sisi kiri atas (logo AGIT), lalu sisi kiri bawah (iconic) dan sisi kanan bawah (logo Digitize Things) yang digambarkan seperti pada ga mbar:

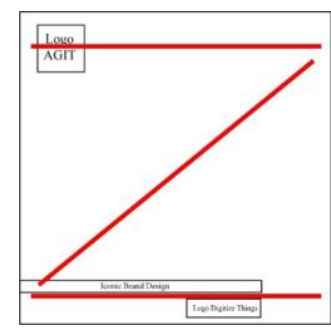

Gambar 7. Desain Layout Sistem ' Z' Secara General

Tahap selanjutnya adalah pembuatan layout untuk template presentasi seperti pada Gambar 8 dan template brosur pada Gambar 9. Icon brand mark yang telah dibuat dikombinasikan dengan 
logo AGIT dan logo slogan Digitize Things menggunakan sistem 'Z' layout yang digambarkan pada Gambar 22. Desain layout tidak hanya dikombinasikan dengan logo, tetapi juga diko mbinasikan dengan gambar foto yang berasal dari stok foto Departemen Marketing dan juga konten teks yang dibuat secara umum dengan "Lorem Ipsum..".

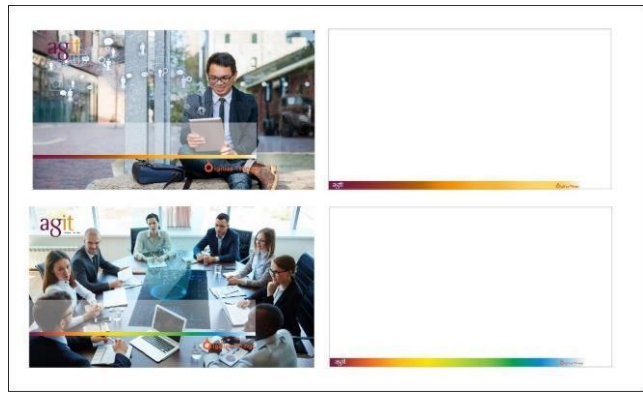

Gambar 8. Hasil Desain Layout Template Presentasi

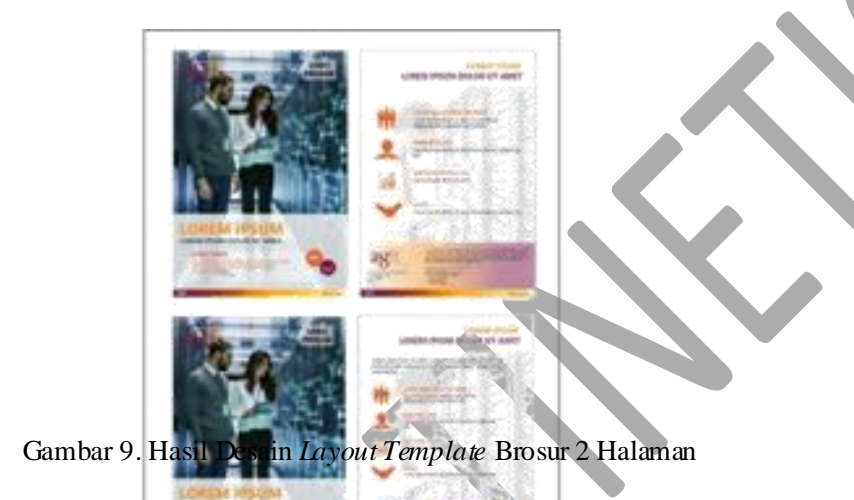

b) ProduksiMotion Graphic

Sesuai dengan hasil diskusi, konsep utama motion graphic yang akan dibuat adalah reveal logo atau menampilkan bentuk logo. Berdasarkan konsep tersebut, digunakan beberapa teknik penggunaan efek, yaitu Turbulent Displace, plugin Trapcode Particular dan Gradient Ramp. Pada produksi motion graphic ini juga dilakukan proses compositing audio dan rendering.

1) Efek Turbulent Displace

Efek turbulent displace digunakan untuk memberi efek distorsi atau pecah pada gambar logo. Efek in i digunakan pada bagian awal motion dimana penerapan efek turbulent displace dilakukan pada shape yang akan meng-cover logo secara keseluruhan. Shape yang digunakan pada tahap ini adalah shape berbentuk lingkaran/ellipse yang diletakkan $\mathrm{di}$ atas layer logo. Untuk menyesuaikan bentuk shape agar berubah distorsi, dilakukan setting pada Amount (54), Size (85) dan Complexity (10) seperti pada Gambar 10.

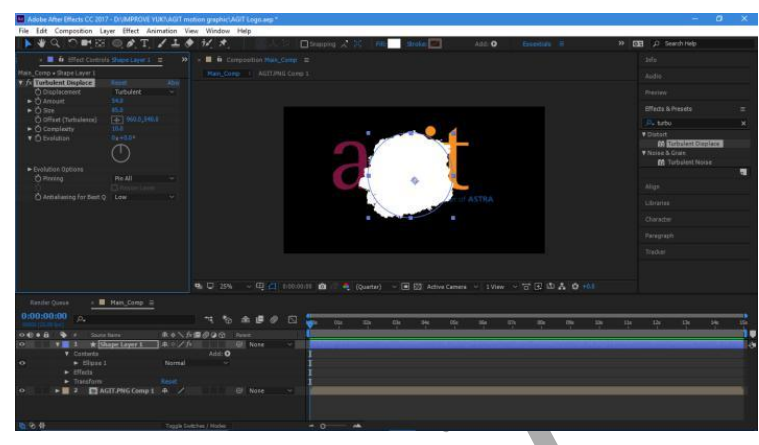

Gambar 10. Efek Turbulent Displace pada Shape Layer

Shape Layer yang telah diberi efek Turbulent Displace kemudian diubah ukurannya dengan scalling hingga memenuhi seluruh layout dan menutupi logo. Scalling ini dilakukan dengan tambahan penggunaan keyframe pada detik 010. Sehingga Shape Layer akan membesar jika timeline digeser ke angka detik yang semakin besar seperti pada Gambar 11.

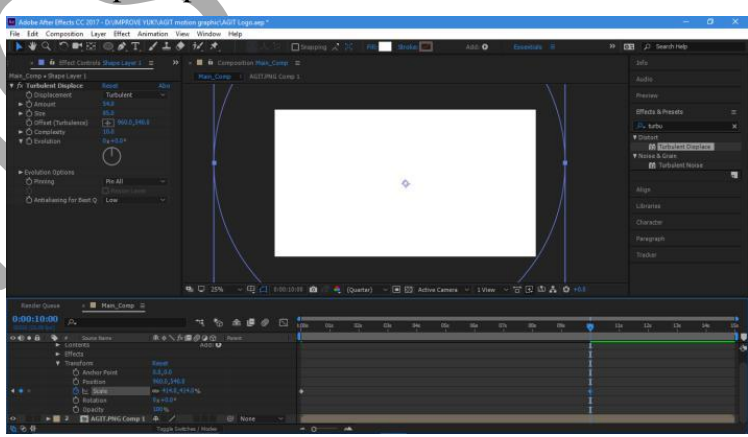

Gambar 11. Pembesaran Ukuran Shape Layer dan Pemberian Keyframe

Layer yang telah diberi efek turbulent displace kemudian di pre-compose menjadi sebuah composition dan diberi Track Matte, dimana layer pertama akan ditransparansikan dengan layer kedua. Proses ini dilakukan beberapa kali hingga menghasilkan hasil seperti pada Gambar 12.

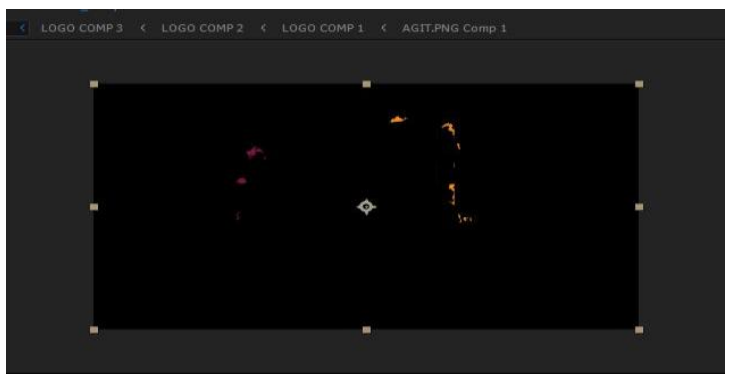

Gambar 12. Hasil Efek Turbulent Displace

2) Plug-in Trapcode Particular

Plug-in Trapcode Particular pada pembuatan motion graphic ini memberikan efek 
partikel yang memancar dan menyebar untuk menampilkan bentuk dari logo. Plug-in ini digunakan pada sebuah layer bernama "particles" yang juga dibuat menjadi sebuah composition. Untuk menggunakan plug-in ini terlebih dahulu harus meng-install plug-in agar dapat berintegrasi dengan After Effects.

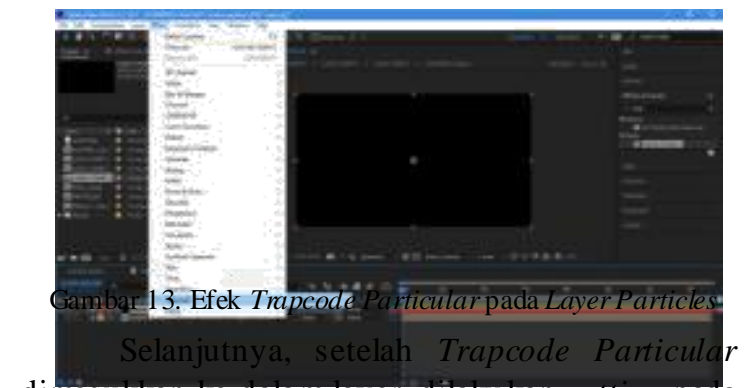

dimasukkan ke dalam layer, dilakukan setting pada bagian efek Emitter, Particles, Shading, PhysicsAir dan Aux System yang merupakan bagian tools yang terdapat pada plug-in ini. Setting tools yang dilakukan akan memberikan efek lebih realistis pada pergerakan partikel yang menyebar seakanakan partikel bergerak hidup untuk menampilkan bentuk asli dari logo. Penerapan Trapcode Particular dan setting tools dilakukan dua kali untuk memberikan efek partikel tambahan di sekitar logo.

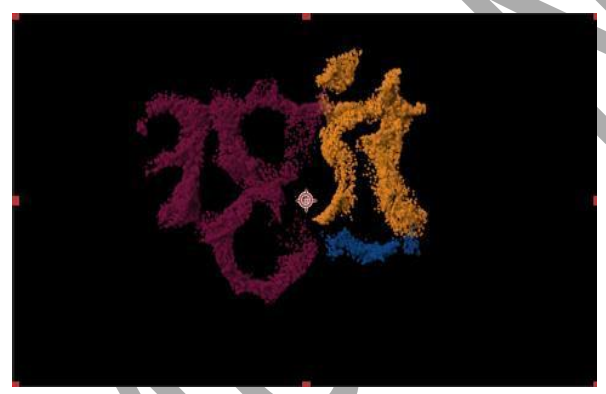

Gambar 14. Hasil Trapcode Particular Tahap 1

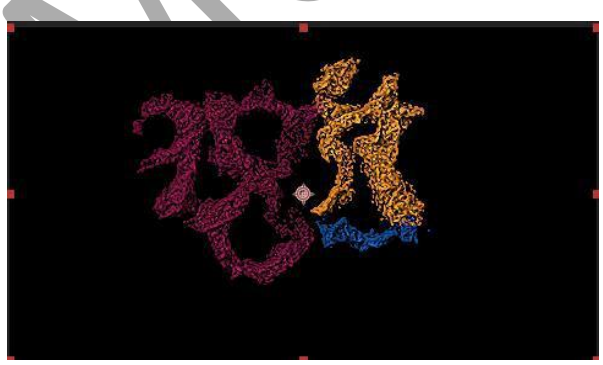

Gambar 15. Hasil Trapcode Particular Tahap 2

Terlihat perbedaan hasil dari pemberian efek Trapcode Particular tahap pertama dengan tahap kedua. Pada tahap kedua, partikel jauh lebih nyata dan hidup dibandingkan dengan hasil pada tahap pertama.

3) Gradient Ramp

Gradient Ramp digunakan pada tahap pembuatan background dari tampilan motion graphic. Tahap awal dari penggunaan efek ini adalah pembuatan solid layer yang akan digunakan sebagai background dengan ukuran resolusi 1920x1080 pixel dan solid layer berwarna hitam.

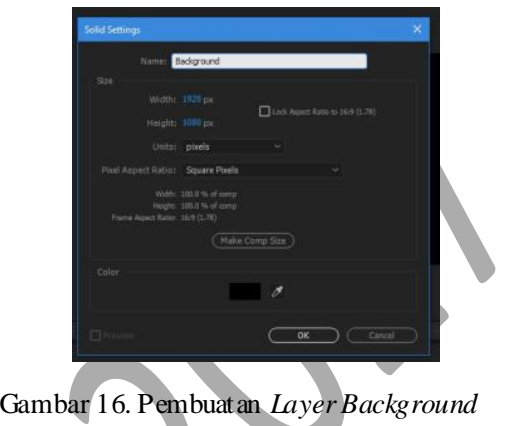

Efek Gradient Ramp diterapkan pada solid layer untuk audio dipotong pada bagian yang telah dipilih menggunakan Razor Tool seperti pada Gambar17. Di bagian akhir audio diberikan efek transisi audio Crossfade - Exponential Fade dan penurunan Audio Gain menjadi -20dB untuk memberikan efek volume audio yang semakin mengecil. Mendapatkan layer berwarna gradient. Untuk membuat background seperti pada hasil Gambar 17 dilakukan setting pada Start Color yang diubah menjadi warna putih, penggunaan jenis efek radial dan penggantian End Color men jadi berwarna abu-abu.

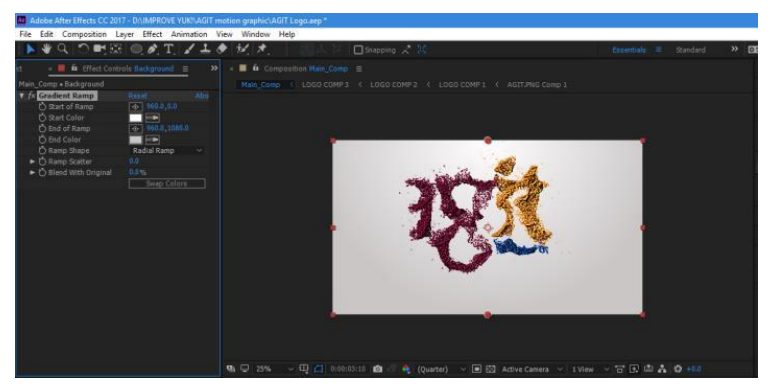

Gambar 17. Setting Efek Gradient Ramp

Untuk memberikan kesan tambahan yang menarik pada hasil motion, diberikan keyframe scalling pada bagian awal dan akhir keyframe. Durasi akhir dari video yang dihasilkan adalah 10 detik.

4) Editing Audio

Editing audio pada motion graphic logo AGIT ini dilakukan menggunakan Adobe Premiere Pro. Editing audio dilakukan bersamaan dengan proses penggabungan audio dan video yang sebelumnya telah di-import ke dalam After Premiere Pro seperti pada Gambar18 dan Gambar 19. 


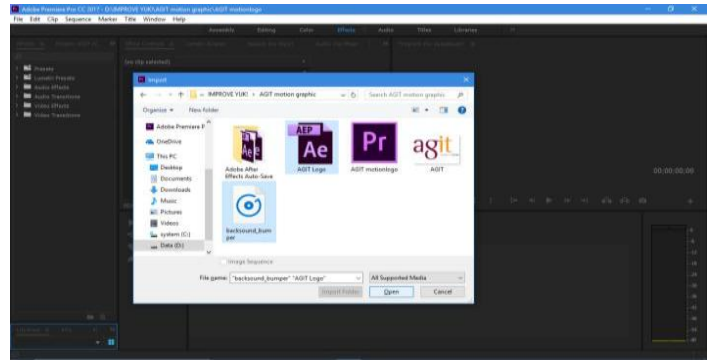

Gambar 18. Proses Import After Effects File dan Audio

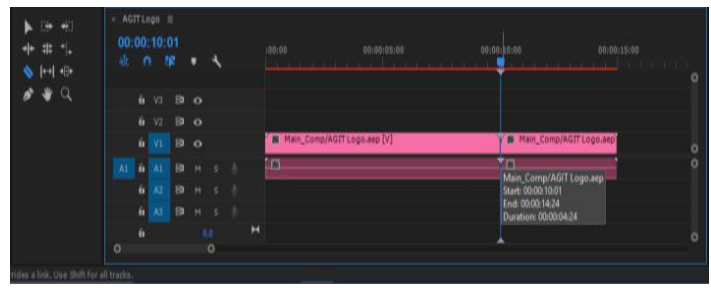

Gambar 19. After Effects File dan Audio

Adobe After Effects file yang telah berada pada Project Window dimasukkan ke dalam timeline untuk dilakukan pengeditan durasi video yang dipotong menggunakan Razor Tool di detik ke-10 seperti pada Gambar 20. Pemotongan bagian video ini dilakukan untuk menghilangkan sisa bagian motion scalling yang terlalu lama setelah efek motion utama berakh ir.

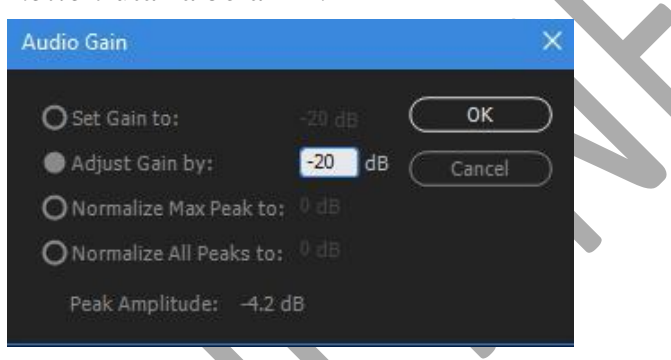

Gambar 20. Pengubahan Transisi Audio Gain

5) Rendering

Tahap selanjutnya yaitu proses rendering yang akan menghasilkan output file video. Rendering dilakukan dengan export file pada Adobe Premiere Pro dengan format file H.264.

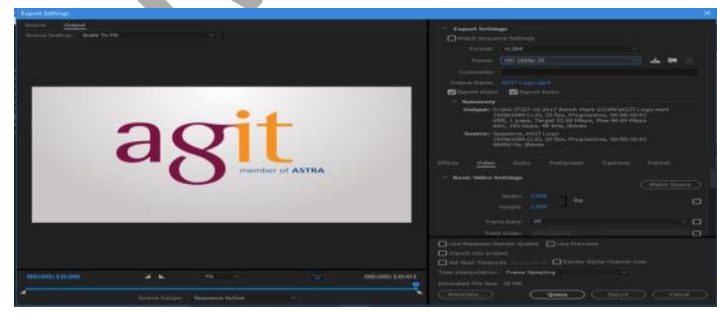

Gambar 21. Tampilan Kotak Dialog Export Setting

C. Paska Produksi

a) Distribusi

1) Brand Mark
Tahap paling akhir dari pembuatan brand mark pada Rebranding Project AGIT adalah tahap distribusi yaitu penerapan brand mark dalam slide master presentasi yang masih termasuk ke dalam produk Rebranding Project. Slide master digunakan sebagai acuan dan template pembuatan Company Profile dan presentasi-presentasi perusahaan lainnya.

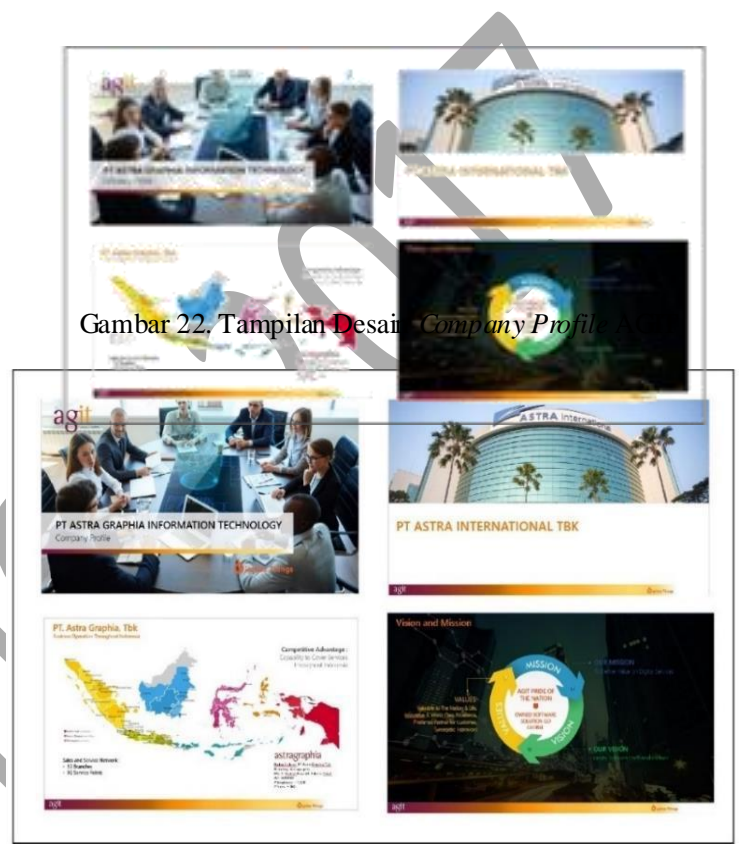

Gambar 23. Tampilan Desain Presentasi QCC Rebranding Project AGIT

\section{2) Motion Graphic}

Dalam tahap akhir pembuatan motion graphic logo AGIT, dilakukan proses distribusi yaitu penyerahan hasil video kepada departemen Marketing. Hasil motion graphic tersebut nantinya akan di-launching oleh Departemen Marketing dalam peresmian Rebranding Project yang akan dilaksanakan di tahun 2018. Motion graphic akan digunakan sebagai bumper dari setiap video review event maupun video perusahaan lainnya.

\section{KESIMPULAN DAN SARAN}

\section{A. Kesimpulan}

Berdasarkan hasil penelitian ini, dapat disimpulkan bahwa:

1. Teknik gradient coloring dan layouting dapat digunakan untuk membuat sebuah brand mark menggunakan Adobe Illutrator.

2. Pembuatan motion graphic logo AGIT menggunakan efek Turbulent Displace, plug-in Trapcode Particular dan efek Gradient Ramp pada Adobe After Effects dengan output video bumper logo berdurasi 10 detik. 
B. Saran

1. Penguasaan dan eksplorasi berbagai tools dalam pembuatan atau pengeditan desain, audio dan video diperlukan agar dapat menghasilkan proyek yang lebih menarik dan berkualitas.

2. Diskusi dan koordinasi dengan supervisor dan tim lainnya yang dilakukan dengan baik dapat membantu penyelesaian pekerjaaan dan kendala yang dihadapi.

\section{REFERENSI}

[1] Bara, A. P. (2017, September 20). Perancangan Rebranding Logo di Laksmi Kebaya Muslimah \& Islamic Wedding Service. (D. Y. Yurisma, Penyunt.)

[2] Maulidi, A. (2016, September 21). Pengertian Brand, Branding dan Rebranding Perusahaan. Diambil kembali dari Kanal Pengetahuan: https://www.kanal.web.id/2016/09/pengertian-brandbranding-rebranding.html

[3] Rangkuti, F. (2002). The Power of Brands. Jakarta: PT Gramedia Pustaka Utama.

[4] Putri, Y. D. (2017). Pembuatan Motion Graphic sebagai Media Sosialisasi danPromosiuntuk Aplikasi Mobile Trading OnlineMandiri Sekuritas. Jurnal Ilmiah Manajemen Informatika dan Komputer Vol. 01, No. 02, 85-92.

[5] Sadono, T. P. (2013). Rebranding Cat Duroll PT Sumber Mas. Jurnal Ruparupa Program Studi Desain Komunikasi Visual Universit as Bunda Mulia Vol. 2, No. 1, 50-59.

[6] Aryakulo. (2016, Juni 6). Mengenal 4 Prinsip Dasar Layout. Diambil kembali dari rizki[dot]id: http://rizki.id/mengenal-4-prinsip-dasar-desain-layout/

[7] Jamie. (2013, Januari 21). Importance of Layout in Graphic Design Materials. Diambil kembali dari designbyjamz:http://www.designzbyjamz.com/importanc e-of-layout-in-graphic-design-materials/

[8] Jago, M. (2012, September 10). The Turbulent Displace Effect. Diambil kembali dari Lynda.com: https://www.lynda.com/Premiere-Protut orials/T urbulent-Displace-effect/123547/133061 $\underline{4 . h \mathrm{ml}}$

[9] Anonim. (2017). What is Trapcode Particular? Diambil kembali dari Redgiant: https://www.redgiant.com/userguide/trapcode-particular/what-is-particular/

[10] Anonim. (2017). Generate Effects. Diambil kembali dariAdobe:https://helpx.adobe.com/aftereffects/using/generate-effects.html

[11] Agarwal, R. (2014). What Is Audio Editing? Diambil kembali dari Audio Shapers: http://www.audioshapers.com/blog/what-is-audioediting.html

[12] Sawa, B. B. (2015, September 08). Cara RenderingVideo PadaPremiere Pro Menggunakan Adobe Encode.

[13] Botello, C. (2013). Adobe Illustrator CS6 Revealed. United States: Cengage Learning.

[14] Dinar, F., \& SW, Y. (2016). Pembuat an User Interface dan Animating pada Media Pembelajaran Interaktif Idiom Bahasa Inggris. Jurnal Mult inetics Vol. 2 No. 1, 3.

[15] Nooryadi, A. (2016, Februari 27). Pengertian Adobe Premiere Pro dan Fungsinya. Diambil kembali dari Ngubek

Ilmu: http://www.ngubekilmu.com/2016/02/adobe-premierepro-edit ing-video.html 


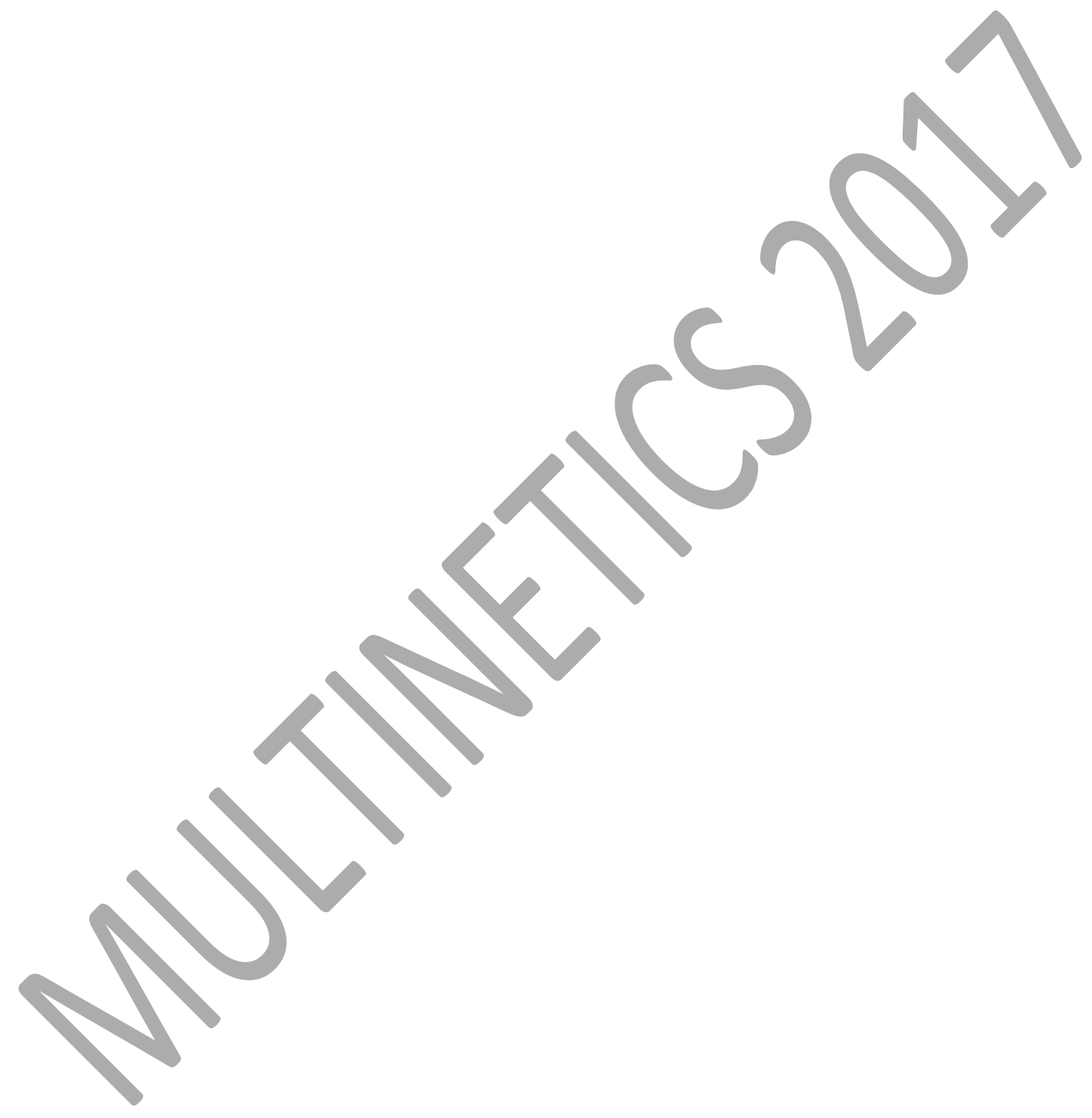

